\title{
Heterogeneity of respiratory distress syndrome: risk factors and morbidity associated with early and late gestation disease
}

Azar Mehrabadi ${ }^{1}{ }^{2 *}$, Sarka Lisonkova ${ }^{1}$ and K.S. Joseph ${ }^{1,3}$

\begin{abstract}
Background: Although respiratory distress syndrome (RDS) is considered a disease of prematurity, there is evidence to suggest heterogeneity between early and late gestation RDS. We examined the epidemiologic features of RDS occurring at early and late gestation.

Methods: We conducted a retrospective cohort study including live births in the United States in 2005-06, with information obtained from the National Center for Health Statistics. Early ( $<32$ weeks) and late gestation RDS ( $\geq 39$ weeks) were contrasted in terms of risk factors and associations with pregnancy complications, obstetric intervention and co-morbidity. Logistic regression was used to quantify the effects of risk factors, while other associations were quantified descriptively.
\end{abstract}

Results: There were 27,971 RDS cases, yielding an incidence of 6.4 per 1000 live births. Early and late gestation RDS differed in terms of risk factors, with factors such as multi-fetal gestation more strongly associated with early (adjusted odds ratio [aOR] 11.6, 95 \% confidence interval 11.0-12.2) compared with late gestation RDS (aOR 3.66, $95 \%$ confidence interval 2.68-4.98). The morbidity correlates of early and late gestation RDS also differed substantially; neonatal seizures were less strongly associated with early (OR 5.90, 95 \% confidence interval 3.67-9.47) compared with late gestation RDS (OR 33.1, $95 \%$ confidence interval 27.2-40.2), while meconium aspiration syndrome was not significantly associated with early gestation RDS (OR 1.87, 95 \% confidence interval 0.94-3.72) and very strongly associated with late gestation RDS (OR 39.8, 95 \% confidence interval 34.7-45.6).

Conclusions: Differences in risk factors and morbidity correlates of early and late gestation RDS suggest that these entities represent two distinct diseases.

Keywords: Respiratory distress syndrome, Respiratory morbidity, Hyaline membrane disease, Preterm, Term newborns, Gestational age, Risk factors

\footnotetext{
* Correspondence: azar.mehrabadi@mail.mcgill.ca

Electronic supplementary materialThe online version of this article

(doi:10.1186/s12884-016-1085-7) contains supplementary material, which is available to authorized users.

'Department of Obstetrics and Gynaecology, University of British Columbia and the Children's and Women's Hospital and Health Centre of British Columbia, Vancouver, BC, Canada

${ }^{2}$ Department of Epidemiology, Biostatistics, and Occupational Health, McGill University, Purvis Hall, 1020 Pine Ave. West, Montreal, QC H3A 1A2, Canada

Full list of author information is available at the end of the article
}

\section{Biomed Central}

(c) 2016 The Author(s). Open Access This article is distributed under the terms of the Creative Commons Attribution 4.0 International License (http://creativecommons.org/licenses/by/4.0/, which permits unrestricted use, distribution, and reproduction in any medium, provided you give appropriate credit to the original author(s) and the source, provide a link to the Creative Commons license, and indicate if changes were made. The Creative Commons Public Domain Dedication waiver (http://creativecommons.org/publicdomain/zero/1.0/) applies to the data made available in this article, unless otherwise stated. 


\section{Background}

Respiratory distress syndrome in the newborn (RDS) is a disease caused by the absence or inadequate production of pulmonary surfactant and the related underdevelopment of the lungs $[1,2]$. The gestational age-specific incidence of RDS has a bimodal distribution, with a first peak in incidence rates at early gestation and a second peak at late term gestation [3]. Such a bimodal pattern of disease incidence has been traditionally interpreted as suggesting disease heterogeneity. For instance, the bimodal age incidence curve of Hodgkin disease was first described by MacMahon in the 1950s and ascribed to etiologic heterogeneity $[4,5]$. Subsequent discoveries, including the detection of Epstein-Barr virus (EBV) DNA in tumour cells, have led to the understanding that the early incidence of Hodgkin disease among young adults is caused by primary infection (non-EBV), while the second peak among older adults is due to loss of immunity to latent infection (mostly EBV) $[6,7]$. Similarly, the bimodal gestational age incidence of RDS suggests that RDS occurring at early and late gestation represents two distinct disease entities [3]. Proposed mechanisms for RDS at term include meconium aspiration syndrome [8], diabetes [9], cesarean delivery, in particular cesarean delivery without labour [10-13], delay in onset of respiration [14], birth asphyxia (neonatal encephalopathy) [14], congenital anomalies [8], and rare genetic mutations of surfactant protein [2].

Newborns with RDS at late term gestation comprise a significant and under-recognized subpopulation of RDS infants [15]. In addition, studies have not adequately characterized RDS at late term, even though the condition was documented in 1959 and has been routinely identified in subsequent years $[8,14,15]$. We hypothesized that the peak in the incidence of RDS at late gestation signifies etiologic and other heterogeneity as compared with early gestation RDS. We therefore carried out a study to describe the risk factors, morbidity correlates and other epidemiologic features of RDS occurring at early and late gestation.

\section{Methods}

The study was a retrospective cohort study of live births in the United States in 2005 and 2006. These years were chosen for the study as they represented the most recent period that information on RDS status was collected on the birth certificate. Information on these infants was obtained from the National Center for Health Statistics birth-infant death (period linked) data files, a set of publically available databases maintained by the US Center for Disease Control [16]. These files included routinely collected demographic information, maternal and infant characteristics, and birth outcomes. Data were uniformly coded according to standard specifications and were edited and reviewed to satisfy quality control standards [16]. We restricted our study to live births for whom information was based on the 1989 revision of the US standard certificate of live birth, as this version included information on whether the infant was diagnosed with RDS. RDS was defined as a diagnosis of hyaline membrane disease recorded in the birth certificate. Further, we excluded live births with a gestational age outside the 24 to 43 weeks range. Gestational age at birth was based on the clinical estimate of gestation, which studies demonstrate to be more accurate than gestational age based on the reported last menstrual period [17, 18].

We first determined the incidence pattern of RDS by gestational age using the fetuses-at-risk approach [3]. For these calculations, gestational age-specific incidence rates were estimated by using number of RDS cases at any gestational week in the numerator and the number of fetuses (at risk of birth and RDS) at that gestation in the denominator. Cases of RDS were also categorized into those that occurred at $<32$ weeks, 32-36 weeks, 37-38 weeks and $\geq 39$ weeks, with the gestational age categories chosen a priori based on the previously described incidence pattern of RDS [3]. The rate of RDS at $<32$ weeks (cumulative incidence between 24 and 31 weeks) was calculated by dividing the number of RDS cases $<32$ weeks by the number of fetuses at 24 weeks, while the rate of RDS at $\geq 39$ weeks (cumulative incidence between 39 and 43 weeks) was calculated by dividing the number of RDS cases $\geq 39$ weeks by the number of fetuses at 39 weeks. The primary analysis contrasting early vs late gestation RDS in terms of risk factors and morbidity focused on early gestation RDS (at $<32$ weeks) and late gestation RDS (at $\geq 39$ weeks).

The fetuses-at-risk approach was used for quantifying the effects of risk factors that were considered to be stable (invariant) through the course of pregnancy from 24 weeks gestation onwards. The fetuses-at-risk approach was preferred for this analysis as risk factors such as older maternal age and chronic hypertension affect fetal growth and birth rates and consequently RDS risk. Gestational age was treated as survival time and took into account the fetalinfant time continuum [19]. Maternal and infant characteristics of interest included maternal age $(<20,20-34$, and $\geq 35$ years), pre-existing or gestational diabetes mellitus, chronic hypertension, multi-fetal gestation, smoking status, congenital anomalies and infant sex. Logistic regression was used to obtain unadjusted and adjusted odds ratios (OR) and $95 \%$ confidence intervals (CI) for each risk factor associated with RDS at early and late gestation for this fetuses-at-risk analysis of invariant risk factors.

Other potential factors with a variable time of onset in early or late pregnancy (e.g., preeclampsia, placental abruption) were not included in the fetuses-at-risk analysis as our data source did not contain information on their gestational age of onset (thus precluding a time 
varying assessment of effects). The relationship between pregnancy complications and obstetric interventions and early versus late gestation RDS was studied among live births. Pregnancy complications included placental abruption, placenta previa, and hypertension in pregnancy, eclampsia, and premature rupture of membranes. Obstetric interventions included labour induction and cesarean delivery. We also examined the morbidity correlates of early vs late gestation RDS among live births by examining the association between RDS and other neonatal morbidity including 5-min Apgar scores ( $<4,4-7$ and $\geq 7$ ), small-forgestational age live birth, neonatal seizures, assisted ventilation $<30 \mathrm{~min}$, assisted ventilation $\geq 30 \mathrm{~min}$, birth asphyxia and meconium aspiration syndrome. Infants born smallfor-gestational age were identified based on birth weightfor-gestational age being less than the 10th percentile of the sex-specific United States national reference for fetal growth [20]. Birth asphyxia [21] was defined as a 5-min Apgar score $<4$, neonatal seizures and receipt of any assisted ventilation. Associations between early (and late) gestation RDS and pregnancy complications, obstetric interventions and other neonatal morbidity, were quantified using ORs and 95 \% CIs calculated among live births in each gestational age category. No adjustment was attempted for this descriptive analysis.

Sensitivity analyses examined associations between risk factors, pregnancy complications, obstetric interventions and co-morbidity and RDS occurring at 32-36 weeks and 37-38 weeks. Sensitivity analyses also assessed whether results changed upon adding fetal deaths to the fetuses-at-risk analyses. All analyses were carried out using SAS version 9.3. This study used publicly available data and did not include patient identifiers; ethical review was therefore not sought.

\section{Results}

Between 2005 and 2006, a total of 4,368,265 live births contained information on RDS status and the risk factors of interest, and were included in the study. Of these, 27,971 received a diagnosis of RDS, yielding a RDS rate of 6.4 per 1000 live births. Most of the RDS cases occurred at 32-36 weeks gestation (42.7\%); $26.6 \%$ occurred at $<32$ weeks, $15.3 \%$ occurred at 37-38 weeks and $15.3 \%$ occurred at $\geq 39$ weeks. The cumulative incidence of RDS by gestational week (which approximates the incidence density of RDS) displayed a bimodal incidence pattern by gestational age, peaking at late preterm gestational, then declining slightly at 37 weeks only to rise again at 39 weeks and beyond (Fig. 1).

\section{Maternal and infant risk factors for early versus late gestation RDS}

The cumulative incidence rate of early gestation RDS (between 24 and 31 weeks, denominator of live births and ongoing pregnancies at 24 weeks) was 1.7 per 1000 fetuses at risk, while the cumulative incidence rate of late gestation RDS (between 39 and 43 weeks, denominator of live births and ongoing pregnancies at 39 weeks) was 1.6 per 1000 fetuses at risk. In unadjusted analyses, maternal age $<20$ years and $\geq 35$ years, multi-fetal gestation, smoking, diabetes, chronic hypertension, small-for-gestational age, congenital anomalies and infant sex were all significantly associated with both early and late gestation RDS (Table 1 ). Older maternal age ( $\geq 35$ years) was significantly associated with early gestation RDS but protective for late gestation RDS.

Adjusted analyses showed that several factors differed in their strength of association with early versus late gestation RDS (Table 2). Diabetes mellitus was weakly

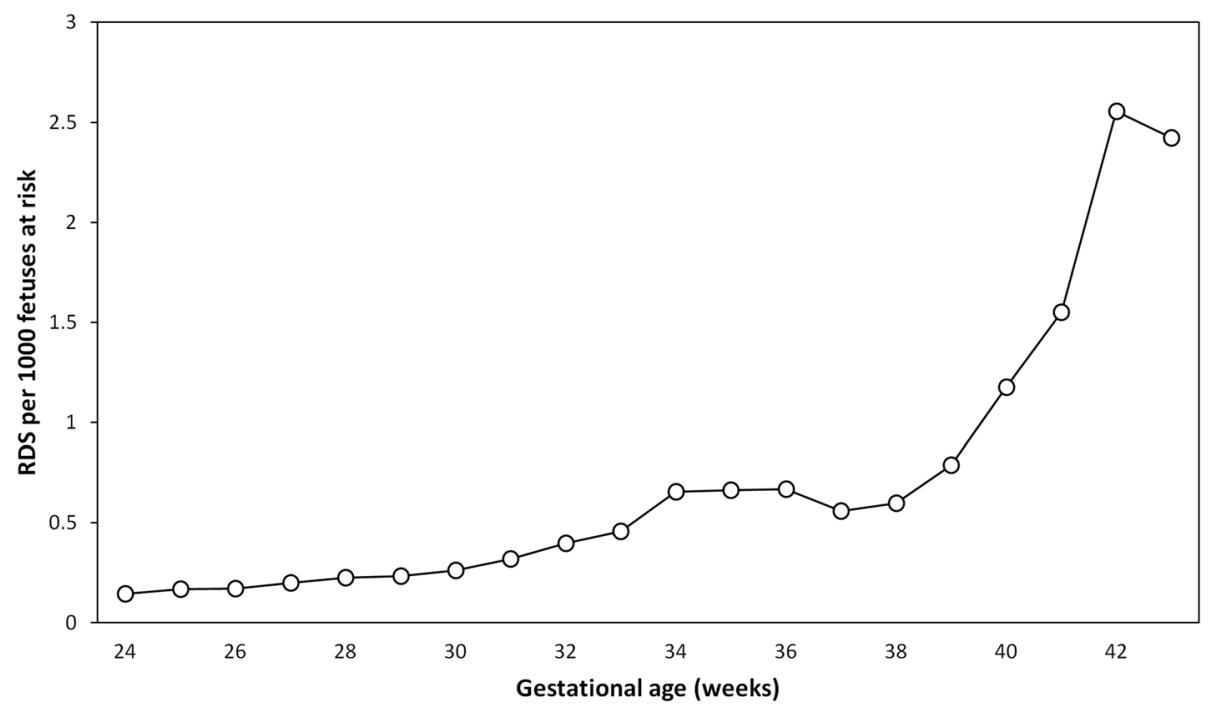

Fig. 1 Gestational age-specific incidence pattern of respiratory distress syndrome (RDS) expressed per 1000 fetuses at risk, United States 2005-06 
Table 1 Rates of respiratory distress syndrome (RDS) per 1000 fetuses at risk at early ( $<32$ weeks) and late $(\geq 39$ weeks) gestation and unadjusted odds ratios and $95 \%$ confidence intervals (CI) expressing the association between maternal and infant characteristics and RDS, United States, 2005-2006

\begin{tabular}{|c|c|c|c|c|c|c|c|c|c|}
\hline \multicolumn{2}{|c|}{ Risk factors } & \multicolumn{4}{|c|}{ RDS $<32$ weeks } & \multicolumn{4}{|c|}{ RDS $\geq 39$ weeks } \\
\hline & & \multirow{2}{*}{$\begin{array}{l}\text { Cases } \\
959\end{array}$} & \multirow{2}{*}{$\begin{array}{l}\text { Fetuses at risk } \\
434,604\end{array}$} & \multirow{2}{*}{$\begin{array}{l}\text { Rate } / 1000^{\mathrm{a}} \\
2.2\end{array}$} & \multirow{2}{*}{$\begin{array}{l}\text { Odds ratios }^{\mathrm{b}}[95 \% \mathrm{Cl}] \\
1.38[1.29,1.48]\end{array}$} & \multirow{2}{*}{$\begin{array}{l}\text { Casess } \\
545\end{array}$} & \multirow{2}{*}{$\frac{\text { Fetuses at risk }}{272,042}$} & \multirow{2}{*}{$\begin{array}{l}\text { Rate } / 1000^{\mathrm{a}} \\
2.0\end{array}$} & \multirow{2}{*}{$\frac{\text { Odds ratios }^{\mathrm{b}}[95 \% \mathrm{Cl}]}{1.25[1.14,1.37]}$} \\
\hline Age & $<20$ years & & & & & & & & \\
\hline & $20-34$ & 5314 & $3,312,305$ & 1.6 & Reference & 3249 & $2,024,271$ & 1.6 & Reference \\
\hline & $\geq 35$ & 1177 & 621,356 & 1.9 & $1.06[1.04,1.08]$ & 493 & 354,606 & 1.4 & $0.95[0.92,0.98]$ \\
\hline \multicolumn{2}{|c|}{ Multi-fetal gestation } & 2169 & 150,761 & 14.4 & $11.6[11.1,12.2]$ & 41 & 7103 & 5.8 & $3.61[2.65,4.91]$ \\
\hline \multicolumn{2}{|c|}{ Smoking } & 1081 & 450,149 & 2.4 & $1.48[1.39,1.58]$ & 582 & 253,288 & 2.3 & $1.49[1.36,1.62]$ \\
\hline \multicolumn{2}{|c|}{ Diabetes } & 445 & 163,802 & 2.7 & $1.63[1.48,1.80]$ & 207 & 74,377 & 2.8 & $1.76[1.53,2.02]$ \\
\hline \multicolumn{2}{|c|}{ Chronic hypertension } & 355 & 47,353 & 7.5 & $4.60[4.13,5.12]$ & 49 & 17,144 & 2.9 & $1.78[1.34,2.36]$ \\
\hline \multicolumn{2}{|c|}{ Congenital anomaly } & 1000 & 64,417 & 15.5 & $10.5[9.83,11.2]$ & 358 & 31,777 & 11.3 & $7.59[6.81,8.46]$ \\
\hline \multicolumn{2}{|c|}{ Male sex } & 4004 & $2,235,753$ & 1.8 & $1.11[1.06,1.16]$ & 2581 & $1,340,148$ & 1.9 & $1.48[1.39,1.57]$ \\
\hline \multicolumn{2}{|l|}{ All } & 7450 & $4,368,265$ & 1.7 & - & 4287 & $2,650,919$ & 1.6 & - \\
\hline
\end{tabular}

${ }^{a}$ Rates of RDS $<32$ weeks represent cumulative incidence from 24 to 31 weeks ( 8 week period) and cannot be directly compared with rates of RDS $\geq 39$ weeks which represent cumulative incidence from 39 to 43 weeks (5 week period)

${ }^{b}$ Odds ratios were estimated by contrasting the RDS rate among those with and those without the risk factor e.g., RDS $<32$ weeks among infants of smokers vs nonsmokers. Since odds ratios express the relative effect of risk factors on RDS, the odds ratios for early gestation RDS can be directly compared with the odds ratios for late gestation RDS

associated with RDS < 32 weeks (OR 1.31, $95 \%$ CI 1.181.44) and more strongly associated with RDS $\geq 39$ weeks (OR 1.74, 95 \% CI 1.51-2.00; P value for heterogeneity of odds ratios <0.05). Similarly, male sex was less strongly associated with RDS <32 weeks (OR 1.09, $95 \%$ CI 1.04-1.14) as compared with RDS $\geq 39$ weeks (OR 1.45, $95 \%$ CI 1.36-1.54; P value for difference in odds ratios $<0.05)$. On the other hand, associations between maternal age $<20$ years, multi-fetal pregnancy, chronic hypertension, and congenital anomalies were stronger

Table 2 Adjusted odds ratios and $95 \%$ confidence intervals (Cl) expressing the association between maternal and infant characteristics and early ( $<32$ weeks) and late ( $\geq 39$ weeks) gestation respiratory distress syndrome (RDS), United States, 2005-2006

\begin{tabular}{llll}
\hline & \multicolumn{2}{l}{ Adjusted odds ratios $[95 \% \mathrm{Cl}]$} \\
\cline { 2 - 4 } & \multicolumn{2}{c}{ RDS $<32$ weeks } & RDS $\geq 39$ weeks \\
\hline Maternal age & $<20$ years & $1.59[1.48,1.71]$ & $1.25[1.14,1.37]$ \\
& $20-34$ & Reference & Reference \\
& 235 & $0.99[0.97,1.01]$ & $0.95[0.92,0.98]$ \\
Multifetal gestation & $11.6[11.0,12.2]$ & $3.66[2.68,4.98]$ \\
Smoking & $1.53[1.43,1.63]$ & $1.44[1.32,1.57]$ \\
Diabetes & $1.31[1.18,1.44]$ & $1.74[1.51,2.00]$ \\
Chronic hypertension & $3.89[3.49,4.35]$ & $1.65[1.25,2.20]$ \\
Any congenital anomaly & $9.41[8.79,10.1]$ & $7.25[6.50,8.09]$ \\
Male sex & $1.09[1.04,1.14]$ & $1.45[1.36,1.54]$ \\
\hline
\end{tabular}

Odds ratios were estimated by contrasting the outcome among those with and those without the risk factor e.g., RDS $<32$ weeks among infants of smokers vs non-smokers with early gestation RDS than with late gestation RDS (Table 2). For instance, chronic hypertension was strongly associated with early gestation RDS (OR 3.89, $95 \%$ CI 3.49-4.35) and moderately associated with late gestation RDS (OR 1.65, 95 \% CI 1.25-2.20).

\section{Pregnancy complications and early versus late gestation RDS}

The rate of RDS among live births $<32$ weeks gestation was 113.2 per 1000 live births, whereas the rate among those born at $\geq 39$ weeks was 1.6 per 1000 live births. Rates of early gestation RDS were significantly higher among live births with pregnancy complications such as placental abruption, placenta previa, hypertension in pregnancy, eclampsia and premature rupture of membranes (Table 3). Rates of late gestation RDS were also significantly higher among women with pregnancy complications compared with women without pregnancy complications. However, the associations between pregnancy complications and early versus late gestation RDS were markedly different and substantially stronger between pregnancy complications and late gestation RDS. For instance, placental abruption was moderately associated with early gestation RDS (OR 1.76, 95 \% CI 1.63-1.90) and strongly associated with late gestation RDS (OR 6.33, 95 \% CI 4.90-8.18; P value for difference in odds ratios $<0.05)$. Similarly, placenta previa, hypertension in pregnancy, eclampsia and premature rupture of membranes were weakly associated with early gestation RDS and strongly associated with late gestation RDS (Table 3). 
Table 3 Rates respiratory distress syndrome (RDS) at early ( $<32$ weeks) and late ( $\geq 39$ weeks) gestation per 1000 live births and unadjusted odds ratios and $95 \%$ confidence intervals (Cl) expressing the association between pregnancy complications and obstetric interventions, and RDS, United States, 2005-2006

\begin{tabular}{|c|c|c|c|c|c|c|}
\hline & \multicolumn{3}{|c|}{ RDS $<32$ weeks } & \multicolumn{3}{|c|}{ RDS $\geq 39$ weeks } \\
\hline & No. & Rate per 1000 & Odds ratio $[95 \% \mathrm{Cl}]$ & No. & Rate per 1000 & Odds ratio $[95 \% \mathrm{Cl}]$ \\
\hline \multicolumn{7}{|l|}{ Pregnancy complications } \\
\hline Placental abruption & 836 & 176 & $1.76[1.63,1.90]$ & 60 & 10 & $6.33[4.90,8.18]$ \\
\hline Placenta previa & 199 & 153.2 & $1.43[1.23,1.67]$ & 25 & 7.2 & $4.51[3.04,6.69]$ \\
\hline Hypertension in pregnancy & 1007 & 154.3 & $1.50[1.39,1.61]$ & 230 & 3.6 & $2.31[2.02,2.63]$ \\
\hline Eclampsia & 287 & 174 & $1.68[1.47,1.91]$ & 27 & 6.9 & $4.33[2.96,6.33]$ \\
\hline Premature rupture of membranes & 1510 & 141.9 & $1.37[1.29,1.46]$ & 107 & 4.2 & $2.65[2.19,3.21]$ \\
\hline \multicolumn{7}{|l|}{ Interventions } \\
\hline Labour induction & 280 & 90.9 & $0.78[0.68,0.88]$ & 1225 & 1.8 & $1.17[1.09,1.25]$ \\
\hline Cesarean delivery & 5146 & 121.9 & $1.28[1.22,1.35]$ & 1881 & 2.8 & $2.27[2.13,2.41]$ \\
\hline Labour induction $^{\mathrm{a}}$ & 115 & 65.8 & $0.70[0.58,0.85]$ & 947 & 1.6 & $1.18[1.09,1.27]$ \\
\hline Cesarean delivery $^{a}$ & 2503 & 94.0 & $1.12[1.05,1.19]$ & 1429 & 2.3 & $2.16[2.02,2.31]$ \\
\hline All live births & 7450 & 113.2 & - & 4287 & 1.6 & - \\
\hline
\end{tabular}

${ }^{a}$ Excluding live births with maternal hypertension, eclampsia, diabetes mellitus, placental abruption, placenta previa and any congenital anomaly

Obstetric interventions and early and late gestation RDS Table 3 also shows the association between labour induction and cesarean delivery and early versus late gestation RDS. Labour induction had a significant protective effect on early gestation RDS and was a significant but weak risk factor for late gestation RDS. Cesarean delivery was significantly associated with both early and late gestation RDS but the effect was substantially larger at late gestation (OR 1.28 vs OR 2.27; $P$ value for difference in odds ratios $<0.05)$. Restricting the analysis to women without pregnancy complications (i.e., without maternal hypertension, eclampsia, diabetes mellitus, placental abruption/previa and congenital anomaly) did not drastically alter the results, although the association between labour induction with early gestation RDS became non-significant.

\section{Morbidity correlates of early and late gestation RDS}

The association between neonatal co-morbidity and early gestation RDS was very different from the association between neonatal co-morbidity and late gestation RDS (Table 4). Apgar score $<4$ at $5 \mathrm{~min}$, small-for-gestational age live birth, and meconium aspiration syndrome were not associated with early gestation RDS, while neonatal seizures, ventilation, and birth asphyxia were strongly associated with early gestational RDS. On the other hand, small-for-gestational age live birth was significantly and moderately associated with late gestation RDS, while the

Table 4 Rates respiratory distress syndrome (RDS) at early (<32 weeks) and late ( $\geq 39$ weeks) gestation per 1000 live births and unadjusted odds ratios and $95 \%$ confidence intervals (Cl) expressing the association between neonatal co-morbidity and RDS, United States, 2005-2006

\begin{tabular}{|c|c|c|c|c|c|c|c|}
\hline & & \multicolumn{3}{|c|}{ RDS $<32$ weeks } & \multicolumn{3}{|c|}{ RDS $\geq 39$ weeks } \\
\hline & & No. & Rate per 1000 & Odds ratio $[95 \% \mathrm{Cl}]$ & No. & Rate per 1000 & Odds ratio $[95 \% \mathrm{Cl}]$ \\
\hline \multirow[t]{3}{*}{ Apgar at $5 \mathrm{~min}$} & $<4$ & 404 & 111.5 & $1.03[0.92,1.14]$ & 108 & 45 & $33.1[27.2,40.2]$ \\
\hline & $4-6$ & 1272 & 142.1 & $1.36[1.27,1.45]$ & 421 & 34.1 & $24.8[22.4,27.5]$ \\
\hline & $\geq 7$ & 5688 & 108.8 & Reference & 3741 & 1.4 & Reference \\
\hline \multicolumn{2}{|c|}{ Small for gestational age } & 786 & 113 & $1.00[0.92,1.08]$ & 562 & 2.6 & $1.73[1.58,1.89]$ \\
\hline \multicolumn{2}{|c|}{ Neonatal seizures } & 30 & 428.6 & $5.90[3.67,9.47]$ & 30 & 22.6 & $14.4[10.0,20.7]$ \\
\hline \multicolumn{2}{|c|}{ Ventilation $\geq 30 \mathrm{~min}$} & 4416 & 320.9 & $7.64[7.26,8.04]$ & 695 & 93.6 & $75.9[69.7,82.6]$ \\
\hline \multicolumn{2}{|c|}{ Ventilation $<30 \mathrm{~min}$} & 503 & 145.4 & $1.36[1.23,1.50]$ & 351 & 9.5 & $6.36[5.70,7.10]$ \\
\hline \multicolumn{2}{|l|}{ Birth asphyxia } & 4983 & 255.5 & $6.20[5.88,6.53]$ & 1106 & 23.5 & $19.7[18.4,21.2]$ \\
\hline \multicolumn{2}{|c|}{ Meconium aspiration syndrome } & 10 & 192.3 & $1.87[0.94,3.72]$ & 228 & 57.6 & $39.8[34.7,45.6]$ \\
\hline \multicolumn{2}{|l|}{ All live births } & 7450 & 113.2 & - & 4287 & 1.6 & - \\
\hline
\end{tabular}

Birth asphyxia was defined as Apgar at $5 \mathrm{~min}<4$, presence of neonatal seizures, or any assisted ventilation. Births with missing Apgar values excluded from the analysis 
other types of neonatal morbidity were all very strongly associated with late gestation RDS. These differences in morbidity correlates between early and late gestation RDs were particularly evident with regard to 5-min Apgar $<4,5$ min Apgar 4-6, neonatal seizures, ventilation $\geq 30 \mathrm{~min}$, birth asphyxia and meconium aspiration syndrome. For example, meconium aspiration syndrome was nonsignificantly associated with early gestation RDS (OR 1.87, $95 \%$ CI 0.94-3.72) but very strongly associated with late gestation RDS (OR 39.8, 95 \% CI 34.7-45.6).

\section{Sensitivity analyses}

The strength of the association between the factors studied and RDS at 32-36 and 37-38 weeks was generally in between that observed with early gestation RDS ( $<32$ weeks) and late gestation RDS ( $\geq 39$ weeks) with some exceptions. Diabetes mellitus was more strongly associated with RDS at 37-38 weeks (OR 2.74, 95 \% CI 2.74-3.03) compared with RDS at other gestational ages. Similarly, the association between congenital anomalies and RDS at 32-36 weeks gestation (OR 4.47, 95 \% CI 4.41-5.09) was stronger than that observed with RDS in other gestational age categories. Associations between placenta previa, eclampsia, premature rupture of membranes and RDS at 37-38 weeks were similar in magnitude to associations between the same complications and RDS at 32-36 weeks, while associations between neonatal co-morbidity and RDS at 37-38 weeks were more similar to associations between neonatal comorbidity and RDS at $\geq 39$ weeks (Appendix Tables 5-8). Sensitivity analyses including stillbirths in the denominator made no marked change in the results or interpretation (Appendix Tables 9-10).

\section{Discussion}

Our study showed that RDS occurring at late term gestation ( $\geq 39$ weeks) constituted an important fraction (15.3\%) of RDS. Early and late gestation RDS differed in terms of potential etiologic factors; maternal and infant characteristics such as maternal age $<20$ years, multi-fetal gestation, chronic hypertension, and congenital anomalies were more strongly associated with early gestation RDS, while factors such as pre-existing diabetes, gestational diabetes and male infant sex were more strongly associated with late gestation RDS. Associations between pregnancy complications, obstetric intervention and neonatal morbidity and early RDS also differed from associations with late gestation RDS. Of particular interest were the differential and very strong associations between late gestation RDS and pregnancy complications (such as placental abruption, placenta previa and eclampsia) and neonatal co-morbidity (especially Apgar $<4$ at $5 \mathrm{~min}$, neonatal seizures, ventilation $\geq 30 \mathrm{~min}$, birth asphyxia and meconium aspiration syndrome). These differences suggest substantial heterogeneity in the etiology, pathologic features and clinical presentation of early and late gestation RDS.

Our findings confirm previous reports that RDS at term is associated with [8-12, 14] meconium aspiration syndrome, diabetes, cesarean delivery, birth asphyxia and congenital anomalies [8-12, 14]. In addition, we identified several other risk factors for RDS $\geq 39$ weeks including multi-fetal gestation, chronic hypertension and male infant sex. The strong associations between late gestation RDS and Apgar $<4$ at $5 \mathrm{~min}$, neonatal seizures, ventilation $\geq 30 \mathrm{~min}$ and birth asphyxia appears to be more consistent with a clinical picture of encephalopathy as opposed to surfactant deficiency or other pulmonary causes. The differential and much stronger associations between pregnancy complications such as placental abruption, placenta previa, and eclampsia and late RDS, suggest that the fetal central nervous system is increasingly susceptible to serious compromise at later gestation. The stronger associations between male sex and small-for-gestational age and late gestation RDS may also indicate a greater susceptibility to encephalopathy [22, 23]. There is a substantial body of animal and human literature showing that the fetal gas exchange and oxygenation is significantly reduced at term gestation and beyond [24-27]. Although uterine artery blood flow increases with gestation, blood flow per unit of fetal weight does not, and arterial partial pressure of oxygen, base excess, oxygen saturation, oxygen content, and arterial partial pressure of carbon dioxide are all reduced at late gestation. The increase in rates of placental complications at late gestation is also congruent with epidemiologic models of stillbirth and perinatal death (which also increase at late gestation) [3].

It is unclear why we observed a negative association between induction and RDS at $<32$ weeks gestation. One possible explanation is that infants induced at $<32$ weeks (as opposed to those that delivered spontaneously at this age) were more likely to have received antenatal corticosteroid therapy, which is protective for RDS [28]. The association between cesarean delivery and RDS at $\geq 39$ weeks gestation is consistent with findings from previous studies [10-13] which have proposed mechanisms such as lung immaturity [13], the lack of hormonal processes that initiate and propagate labour and which may be involved in lung function, and the effects of labour and vaginal delivery in clearing lung fluid [29].

The limitations of our study include the absence of information on maternal infection and severity of respiratory distress syndrome. In addition, the information in our data source was obtained through routine abstraction and hence may have been subject to some coding variation and transcription errors. However, these problems are likely to have been non-differential by gestational age and RDS status and hence would have had a limited impact on our findings. 


\section{Conclusions}

Our study shows that a significant fraction of RDS occurs at late term gestation. Risk factors such as maternal age, pre-existing and gestational diabetes mellitus, multi-fetal gestation, chronic hypertension and infant sex are differently associated with early and late gestation RDS. Also, the associations between pregnancy complications, and neonatal co-morbidity (that are components of neonatal encephalopathy) are much stronger with late gestation RDS as compared with early gestation RDS. The clinico-epidemiologic picture associated with early and late gestation RDS suggests that these two conditions are distinct disease entities. Further research elucidating the pathogenesis of late gestation RDS will help to clarify the management options for better treating this condition.

\section{Appendix}

Table 5 Rates of respiratory distress syndrome (RDS) at 32-36 weeks and 37-38 weeks per 1000 fetuses at risk and unadjusted odds ratios and $95 \%$ confidence intervals (Cl) expressing the association between maternal and infant characteristics and RDS, United States, 2005-2006

\begin{tabular}{|c|c|c|c|c|c|c|c|c|c|}
\hline \multirow{2}{*}{\multicolumn{2}{|c|}{ Risk factors }} & \multicolumn{4}{|c|}{ RDS 32-36 weeks } & \multicolumn{4}{|c|}{ RDS 37-38 weeks } \\
\hline & & \multirow{2}{*}{$\begin{array}{l}\text { Cases } \\
1165\end{array}$} & \multirow{2}{*}{$\frac{\text { Fetuses at risk }}{426,327}$} & \multirow{2}{*}{$\begin{array}{l}\text { Rate } / 1000^{a} \\
2.7\end{array}$} & \multirow{2}{*}{$\begin{array}{l}\text { Odds ratios }^{\mathrm{b}}[95 \% \mathrm{Cl}] \\
1.00[0.94,1.06]\end{array}$} & \multirow{2}{*}{$\begin{array}{l}\text { Cases } \\
360\end{array}$} & \multirow{2}{*}{$\begin{array}{l}\text { Fetuses at risk } \\
386,323\end{array}$} & \multirow{2}{*}{$\begin{array}{l}\text { Rate/1000 } \\
0.93\end{array}$} & \multirow{2}{*}{$\begin{array}{l}\text { Odds ratios }^{\mathrm{b}}[95 \% \mathrm{Cl}] \\
0.83[0.74,0.92]\end{array}$} \\
\hline Age & $<20$ years & & & & & & & & \\
\hline & $20-34$ & 8969 & $3,265,775$ & 2.7 & Reference & 3364 & $2,978,793$ & 1.13 & Reference \\
\hline & $\geq 35$ & 1808 & 610,342 & 3.0 & $1.03[1.01,1.04]$ & 568 & 545,748 & 1.04 & $0.97[0.95,1.00]$ \\
\hline \multicolumn{2}{|c|}{ Multi-fetal gestation } & 2770 & 133,526 & 20.7 & $9.61[9.21,10.0]$ & 214 & 55,869 & 3.83 & $3.63[3.16,4.17]$ \\
\hline \multicolumn{2}{|c|}{ Smoking } & 1613 & 441,604 & 3.7 & $1.37[1.30,1.44]$ & 632 & 392,595 & 1.61 & $1.55[1.42,1.69]$ \\
\hline \multicolumn{2}{|c|}{ Diabetes mellitus } & 996 & 160,801 & 6.2 & $2.35[2.20,2.51]$ & 414 & 136,882 & 3.02 & $2.95[2.67,3.27]$ \\
\hline \multicolumn{2}{|c|}{ Chronic hypertension } & 423 & 44,759 & 9.5 & $3.52[3.19,3.88]$ & 126 & 35,036 & 3.60 & $3.35[2.81,4.01]$ \\
\hline \multicolumn{2}{|c|}{ Congenital anomaly } & 832 & 61,034 & 13.6 & $5.26[4.90,5.65]$ & 346 & 50,707 & 6.82 & $6.71[6.01,7.50]$ \\
\hline \multicolumn{2}{|c|}{ Male sex } & 7130 & $2,200,877$ & 3.2 & $1.42[1.37,1.47]$ & 2739 & $1,994,128$ & 1.37 & $1.70[1.59,1.81]$ \\
\hline \multicolumn{2}{|l|}{ All } & 11,942 & $4,302,444$ & 2.8 & - & 4292 & $3,910,864$ & 1.10 & - \\
\hline
\end{tabular}

${ }^{a}$ Rates of RDS $<32$ weeks represent cumulative incidence from 24 to 31 weeks (8 week period) and cannot be directly compared with rates of RDS $\geq 39$ weeks which represent cumulative incidence from 39 to 43 weeks (5 week period)

${ }^{b}$ Odds ratios were estimated by contrasting the RDS rate among those with and those without the risk factor e.g., RDS $<32$ weeks among infants of smokers vs nonsmokers. Since odds ratios express the relative effect of risk factors on RDS, the odds ratios for early gestation RDS can be directly compared with the odds ratios for late gestation $\mathrm{RDS}$

Table 6 Adjusted odds ratios and $95 \%$ confidence intervals (Cl) expressing the association between maternal and infant characteristics and respiratory distress syndrome (RDS) at 32-36 weeks and 37-38 weeks, United States, 2005-2006

\begin{tabular}{|c|c|c|c|}
\hline & & \multicolumn{2}{|c|}{ Adjusted odds ratios [95\% Cl] } \\
\hline & & RDS 32-36 weeks & RDS 37-38 weeks \\
\hline \multirow[t]{3}{*}{ Maternal age } & $<20$ years & $1.14[1.07,1.21]$ & $0.86[0.78,0.96]$ \\
\hline & $20-34$ & Reference & Reference \\
\hline & $\geq 35$ & $0.97[0.95,0.98]$ & $0.95[0.92,0.97]$ \\
\hline Multi-fetal gestation & & $9.6[9.2,10.0]$ & $3.65[3.18,4.20]$ \\
\hline Smoking & & $1.42[1.35,1.50]$ & $1.55[1.42,1.68]$ \\
\hline Diabetes mellitus & & $2.04[1.90,2.18]$ & $2.71[2.45,3.01]$ \\
\hline Chronic hypertension & & $2.86[2.59,3.16]$ & $2.74[2.29,3.28]$ \\
\hline Any congenital anomaly & & $4.81[4.48,5.17]$ & $6.22[5.57,6.94]$ \\
\hline Male sex & & $1.41[1.36,1.46]$ & $1.67[1.57,1.77]$ \\
\hline
\end{tabular}


Table 7 Rates respiratory distress syndrome (RDS) at 32-36 weeks and 37-38 weeks per 1000 live births and unadjusted odds ratios and $95 \%$ confidence intervals (Cl) expressing the association between pregnancy complications and obstetric interventions, and RDS at 32-36 weeks and 37-38 weeks, United States, 2005-2006

\begin{tabular}{|c|c|c|c|c|c|c|}
\hline & \multicolumn{3}{|c|}{ RDS 32-36 weeks } & \multicolumn{3}{|c|}{ RDS 37-38 weeks } \\
\hline & No. & Rate per 1000 & Odds ratio $[95 \% \mathrm{Cl}]$ & No. & Rate per 1000 & Odds ratio $[95 \% \mathrm{Cl}]$ \\
\hline \multicolumn{7}{|l|}{ Pregnancy complications } \\
\hline Placental abruption & 645 & 78.0 & $2.79[2.57,3.03]$ & 102 & 17.9 & $5.43[4.45,6.62]$ \\
\hline Placenta previa & 348 & 63.8 & $2.20[1.97,2.46]$ & 44 & 9.0 & $2.67[1.98,3.59]$ \\
\hline Hypertension in pregnancy & 1748 & 44.1 & $1.55[1.47,1.63]$ & 449 & 6.8 & $2.12[1.92,2.34]$ \\
\hline Eclampsia & 321 & 58.0 & $1.98[1.77,2.22]$ & 43 & 8.9 & $2.66[1.97,3.59]$ \\
\hline Premature rupture of membranes & 1430 & 46.3 & $1.62[1.53,1.71]$ & 104 & 6.3 & $1.88[1.55,2.29]$ \\
\hline \multicolumn{7}{|l|}{ Interventions } \\
\hline Labour induction & 1455 & 26.6 & $0.85[0.81,0.90]$ & 953 & 3.6 & $1.08[1.00,1.16]$ \\
\hline Labour induction ${ }^{a}$ & 697 & 20.7 & $0.80[0.74,0.87]$ & 586 & 2.9 & $1.07[0.98,1.17]$ \\
\hline Cesarean delivery & 6971 & 40.7 & $1.84[1.77,1.91]$ & 2340 & 5.7 & $2.48[2.34,2.64]$ \\
\hline Cesarean delivery $^{a}$ & 3826 & 32.8 & $1.64[1.57,1.72]$ & 1512 & 4.5 & $2.32[2.16,2.49]$ \\
\hline All live births & 11,942 & 30.5 & - & 4292 & 3.4 & - \\
\hline
\end{tabular}

Odds ratios were estimated by contrasting outcomes among those with and those without the risk factor e.g., RDS at 37-38 weeks among infants of women delivering with placental abruption vs. infants of women without placental abruption

${ }^{a}$ Excluding live births with maternal hypertension, eclampsia, diabetes mellitus, placental abruption, placenta previa and any congenital anomaly

Table 8 Rates respiratory distress syndrome (RDS) at 32-36 weeks and 37-38 weeks per 1000 live births among infants with other neonatal morbidity, and unadjusted odds ratios and $95 \%$ confidence intervals (Cl) expressing the association between neonatal comorbidity and RDS at 32-36 weeks and 37-38 weeks, United States, 2005-2006

\begin{tabular}{|c|c|c|c|c|c|c|c|}
\hline & & \multicolumn{3}{|c|}{ RDS 32-36 weeks } & \multicolumn{3}{|c|}{ RDS 37-38 weeks } \\
\hline & & No. & Rate per 1000 & Odds ratio $[95 \% \mathrm{Cl}]$ & $\overline{\text { No. }}$ & Rate per 1000 & Odds ratio $[95 \% \mathrm{Cl}]$ \\
\hline \multirow[t]{3}{*}{ Apgar at 5 minutes } & $<4$ & 165 & 85.2 & $3.13[2.67,3.68]$ & 50 & 34.5 & $11.4[8.6,15.1]$ \\
\hline & $4-6$ & 733 & 99.9 & $3.73[3.45,4.04]$ & 309 & 45.1 & $15.0[13.3,16.9]$ \\
\hline & $\geq 7$ & 11,009 & 28.9 & Reference & 3917 & 3.1 & Reference \\
\hline \multicolumn{2}{|c|}{ Small for gestational age } & 2202 & 32.7 & $1.09[1.04,1.14]$ & 645 & 4.8 & $1.48[1.36,1.61]$ \\
\hline \multicolumn{2}{|l|}{ Neonatal seizures } & 27 & 102.3 & $3.63[2.44,5.40]$ & 12 & 20.1 & $6.04[3.41,10.70]$ \\
\hline \multicolumn{2}{|l|}{ Ventilation $\geq 30 \mathrm{~min}$} & 3428 & 236.1 & $13.4[12.8,14.0]$ & 858 & 144.4 & $61.5[56.8,66.6]$ \\
\hline \multicolumn{2}{|l|}{ Ventilation $<30 \mathrm{~min}$} & 766 & 64.9 & $2.29[2.12,2.47]$ & 294 & 16.3 & $5.14[4.56,5.79]$ \\
\hline \multicolumn{2}{|l|}{ Birth asphyxia } & 4244 & 153.1 & $8.37[8.05,8.71]$ & 1175 & 46.3 & $19.2[18.0,20.6]$ \\
\hline \multicolumn{2}{|c|}{ Meconium aspiration syndrome } & 38 & 140.7 & $5.22[3.70,7.36]$ & 66 & 72.8 & $23.3[18.1,30.0]$ \\
\hline \multicolumn{2}{|l|}{ All live births } & 11,942 & 30.5 & - & 4292 & 3.4 & - \\
\hline
\end{tabular}

Birth asphyxia was defined as Apgar at 5 minute $<4$, presence of neonatal seizures, or any assisted ventilation. Births with missing Apgar values excluded from the analysis. Odds ratios were estimated by contrasting outcomes among those with and those without the risk factor e.g., RDS at 37-38 weeks among infants with and without meconium aspiration syndrome

Table 9 Sensitivity analysis including stillbirths: Crude odds ratios and $95 \%$ confidence intervals (Cl) expressing the association between early antepartum characteristics and respiratory distress syndrome (RDS), United States, 2005-2006

\begin{tabular}{|c|c|c|c|c|c|}
\hline & & \multicolumn{4}{|c|}{ Unadjusted odds ratios [95 \% Cl] } \\
\hline & & RDS $<32$ weeks & RDS 32-36 weeks & RDS $37-38$ weeks & $\overline{R D S} \geq 39$ weeks \\
\hline \multirow[t]{3}{*}{ Maternal age } & $<20$ years & $1.38[1.29,1.48]$ & $1.00[0.94,1.06]$ & $0.83[0.74,0.92]$ & $1.25[1.14,1.37]$ \\
\hline & $20-34$ & Reference & Reference & Reference & Reference \\
\hline & $\geq 35$ & $1.06[1.04,1.08]$ & $1.03[1.01,1.04]$ & $0.97[0.95,1.00]$ & $0.95[0.92,0.98]$ \\
\hline \multicolumn{2}{|c|}{ Multifetal gestation } & $11.6[11.1,12.2]$ & $9.60[9.20,10.0]$ & $3.63[3.16,4.17]$ & $3.60[2.65,4.91]$ \\
\hline \multicolumn{2}{|l|}{ Smoking } & $1.48[1.38,1.58]$ & $1.37[1.30,1.44]$ & $1.55[1.42,1.68]$ & $1.49[1.36,1.62]$ \\
\hline \multicolumn{2}{|l|}{ Diabetes } & $1.63[1.48,1.79]$ & $2.35[2.20,2.51]$ & $2.95[2.66,3.26]$ & $1.76[1.53,2.02]$ \\
\hline \multicolumn{2}{|c|}{ Chronic hypertension } & $4.57[4.10,5.08]$ & $3.51[3.18,3.87]$ & $3.35[2.81,4.00]$ & $1.78[1.34,2.36]$ \\
\hline \multicolumn{2}{|c|}{ Any congenital anomaly } & $10.3[9.61,11.0]$ & $5.20[4.84,5.58]$ & $6.67[5.97,7.45]$ & $7.55[6.78,8.42]$ \\
\hline \multicolumn{2}{|l|}{ Male sex } & $1.11[1.06,1.16]$ & $1.42[1.37,1.47]$ & $1.70[1.59,1.81]$ & $1.48[1.39,1.57]$ \\
\hline
\end{tabular}


Table 10 Sensitivity analysis including stillbirths: Adjusted odds ratios and $95 \%$ confidence intervals (Cl) expressing the association between early antepartum characteristics and respiratory distress syndrome (RDS), United States, 2005-2006

\begin{tabular}{|c|c|c|c|c|c|}
\hline & & Adjusted odds ra & $\mathrm{Cl}]$ & & \\
\hline & & RDS $<32$ weeks & RDS 32-36 weeks & RDS 37-38 weeks & RDS $\geq 39$ weeks \\
\hline Maternal age & $<20$ years & $1.59[1.48,1.71]$ & $1.14[1.07,1.21]$ & $0.86[0.78,0.96]$ & $1.25[1.14,1.37]$ \\
\hline & $20-34$ & Reference & Reference & Reference & Reference \\
\hline & $\geq 35$ & $0.99[0.97,1.01]$ & $0.97[0.95,0.98]$ & $0.95[0.92,0.97]$ & $0.95[0.92,0.98]$ \\
\hline Multifetal ges & & $11.6[11.0,12.2]$ & $9.61[9.20,10.0]$ & $3.65[3.18,4.20]$ & $3.66[2.68,4.98]$ \\
\hline Smoking & & $1.53[1.43,1.63]$ & $1.42[1.35,1.50]$ & $1.55[1.42,1.68]$ & $1.44[1.32,1.57]$ \\
\hline Diabetes & & $1.31[1.18,1.44]$ & $2.04[1.90,2.18]$ & $2.71[2.45,3.01]$ & $1.74[1.51,2.00]$ \\
\hline Chronic hype & & $3.89[3.49,4.35]$ & $2.86[2.59,3.16]$ & $2.74[2.29,3.28]$ & $1.65[1.25,2.20]$ \\
\hline Any congenit & & $9.4[8.79,10.1]$ & $4.81[4.48,5.17]$ & $6.22[5.57,6.94]$ & $7.25[6.50,8.09]$ \\
\hline Male sex & & $1.09[1.04,1.14]$ & $1.41[1.36,1.46]$ & $1.67[1.57,1.77]$ & $1.45[1.36,1.54]$ \\
\hline
\end{tabular}

\section{Abbreviations}

Cl: Confidence interval; OR: Odds ratio; RDS: Respiratory distress syndrome

\section{Acknowledgements}

K.S. Joseph is supported by an Investigator award from the Child and Family Research Institute and a Canadian Institutes of Health Research (CIHR) Chair in maternal, fetal and infant health services research (APR-126338). Azar Mehrabadi is supported by a CIHR postdoctoral fellowship.

\section{Funding}

This work is supported by a Canadian Institutes of Health Research (ClHR) Team grant in Severe Maternal Morbidity (MAH-115445). The funders had no role in the design of the study, the interpretation of data or writing of the manuscript.

\section{Availability of data and materials}

Information on these infants was obtained from the National Center for Health Statistics birth-infant death (period linked) data files, a set of publically available databases maintained by the US Center for Disease Control (http:// www.cdc.gov/nchs).

\section{Authors' contributions}

AM conceptualized and designed the study, carried out the analyses, drafted the initial manuscript, and approved the final manuscript as submitted. SL conceptualized and designed the study, reviewed and revised the manuscript and approved the final manuscript as submitted. KS」 conceptualized and designed the study, reviewed and revised the manuscript and approved the final manuscript as submitted.

\section{Competing interests}

All authors declare that they have no competing interests.

\section{Consent for publication}

Not applicable as this study does not contain individual level data.

\section{Ethics approval and consent to participate}

This study used publicly available data and did not include patient identifiers; ethical review was therefore not sought.

\section{Author details}

'Department of Obstetrics and Gynaecology, University of British Columbia and the Children's and Women's Hospital and Health Centre of British Columbia, Vancouver, BC, Canada. ²Department of Epidemiology, Biostatistics, and Occupational Health, McGill University, Purvis Hall, 1020 Pine Ave. West, Montreal, QC H3A 1A2, Canada. ${ }^{3}$ School of Population and Public Health, University of British Columbia, Vancouver, BC, Canada.

Received: 9 October 2015 Accepted: 16 September 2016 Published online: 27 September 2016

\section{References}

1. Bahadue FL, Soll R. Early versus delayed selective surfactant treatment for neonatal respiratory distress syndrome. Cochrane Database Syst Rev. 2012;11:CD001456.

2. Sweet DG, Carnielli V, Greisen G, Hallman M, Ozek E, Plavka R, Saugstad OD, Simeoni U, Speer CP, Halliday HL. European consensus guidelines on the management of neonatal respiratory distress syndrome in preterm infants-2010 update. Neonatology. 2010;97(4):402-17.

3. Joseph KS. The natural history of pregnancy: diseases of early and late gestation. Br J Obstet Gynaecol. 2011;118(13):1617-29.

4. Macmahon B. Epidemiological evidence of the nature of Hodgkin's disease. Cancer. 1957;10(5):1045-54.

5. MacMahon B. Epidemiology of Hodgkin's disease. Cancer Res. 1966:26(6):1189-201.

6. Hjalgrim $H$, Engels EA. Infectious aetiology of Hodgkin and non-Hodgkin Iymphomas: a review of the epidemiological evidence. J Intern Med. 2008;264(6):537-48.

7. Jarrett RF. Viruses and lymphoma/leukaemia. J Pathol. 2006:208(2):176-86.

8. Clark RH. The epidemiology of respiratory failure in neonates born at an estimated gestational age of 34 weeks or more. J Perinatol. 2005;25(4):251-7.

9. Robert MF, Neff RK, Hubbell JP, Taeusch HW, Avery ME. Association between maternal diabetes and the respiratory-distress syndrome in the newborn. N Engl J Med. 1976;294(7):357-60.

10. Hales KA, Morgan MA, Thurnau GR. Influence of labor and route of delivery on the frequency of respiratory morbidity in term neonates. Int J Gynaecol Obstet. 1993:43(1):35-40

11. Madar J, Richmond S, Hey E. Surfactant-deficient respiratory distress after elective delivery at 'term'. Acta Paediatr. 1999:88(11):1244-8.

12. Krantz ME, Wennergren $M$, Bengtson $L G$, Hjalmarson $O$, Karlsson $K$, Sellgren $U$. Epidemiological analysis of the increased risk of disturbed neonatal respiratory adaptation after caesarean section. Acta Paediatr Scand. 1986;75(5):832-9.

13. Hansen AK, Wisborg K, Uldbjerg N, Henriksen TB. Risk of respiratory morbidity in term infants delivered by elective caesarean section: cohort study. Br Med J. 2008;336(7635):85-7.

14. James LS. Physiology of respiration in newborn infants and in the respiratory distress syndrome. Pediatrics. 1959;24:1069-101.

15. Wang ML, Dorer DJ, Fleming MP, Catlin EA. Clinical outcomes of near-term infants. Pediatrics. 2004;114(2):372-6.

16. Public Use Data File Documentation: 2005 Period Linked Birth/Infant Death Data Set. http://www.cdc.gov/nchs/data_access/VitalStatsOnline.htm. Accessed 1 Dec 2015.

17. Callaghan WM, Dietz PM. Differences in birth weight for gestational age distributions according to the measures used to assign gestational age Am J Epidemiol. 2010;171(7):826-36.

18. Joseph KS, Huang L, Liu S, Ananth CV, Allen AC, Sauve R, Kramer MS. Reconciling the high rates of preterm and postterm birth in the United States. Obstet Gynecol. 2007;109(4):813-22.

19. Joseph KS. Theory of obstetrics: the fetuses-at-risk approach as a causal paradigm. J Obstet Gynaecol Can. 2004;26(11):953-60.

20. Alexander GR, Himes JH, Kaufman RB, Mor J, Kogan M. A United States national reference for fetal growth. Obstet Gynecol. 1996;87(2):163-8. 
21. Dzakpasu S, Joseph KS, Huang L, Allen A, Sauve R, Young D. Decreasing diagnoses of birth asphyxia in Canada: fact or artifact. Pediatrics. 2009;123(4):e668-72.

22. Hayes BC, McGarvey C, Mulvany S, Kennedy J, Geary MP, Matthews TG, King MD. A case-control study of hypoxic-ischemic encephalopathy in newborn infants at >36 weeks gestation. Am J Obstet Gynecol. 2013;209(1):29 e1-e19.

23. Badawi N, Kurinczuk JJ, Keogh JM, Alessandri LM, O'Sullivan F, Burton PR Pemberton PJ, Stanley FJ. Antepartum risk factors for newborn encephalopathy: the Western Australian case-control study. Br Med J. 1998;317(7172):1549-53.

24. Ferrazzi E, Rigano S, Padoan A, Boito S, Pennati G, Galan HL. Uterine artery blood flow volume in pregnant women with an abnormal pulsatility index of the uterine arteries delivering normal or intrauterine growth restricted newborns. Placenta. 2011;32(7):487-92.

25. Goldkrand JW, Moore DH, Lentz SU, Clements SP, Turner AD, Bryant JL. Volumetric flow in the umbilical artery: normative data. J Matern Fetal Med. 2000;9(4):224-8.

26. Konje JC, Kaufmann P, Bell SC, Taylor DJ. A longitudinal study of quantitative uterine blood flow with the use of color power angiography in appropriate for gestational age pregnancies. Am J Obstet Gynecol. 2001;185(3):608-13.

27. Thaler I, Manor D, Itskovitz J, Rottem S, Levit N, Timor-Tritsch I, Brandes JM. Changes in uterine blood flow during human pregnancy. Am J Obstet Gynecol. 1990;162(1):121-5.

28. Altman M, Vanpee M, Cnattingius S, Norman M. Risk factors for acute respiratory morbidity in moderately preterm infants. Paediatr Perinat Epidemiol. 2013;27(2):172-81.

29. Bland RD. Loss of liquid from the lung lumen in labor: more than a simple "squeeze". Am J Physiol Lung Cell Mol Physiol. 2001;280(4):L602-5.

\section{Submit your next manuscript to BioMed Central and we will help you at every step:}

- We accept pre-submission inquiries

- Our selector tool helps you to find the most relevant journal

- We provide round the clock customer support

- Convenient online submission

- Thorough peer review

- Inclusion in PubMed and all major indexing services

- Maximum visibility for your research

Submit your manuscript at www.biomedcentral.com/submit 